\title{
El asedio a las autonomías indígenas por el modelo minero extractivo en México
} The siege of indigenous autonomies due
to the extractive mining model in Mexico

\author{
Laura R. Valladares de la Cruz* \\ Universidad Autónoma Metropolitana Iztapalapa, Ciudad de México, México \\ https://orcid.org/o000-0002-7577-6300
}

ISSN: ISSN-OI85-4259; e- ISSN: 2007-9I76 DoI: http://dx.doi.org/ro.28928/revistaiztapalapa/852018/atc5/valladaresdelacruzlr

\begin{abstract}
Resumen
Este artículo se propone presentar un panorama general sobre los impactos que tiene en las autonomías indígenas el giro extractivista minero que se ha puesto en marcha en México y que se ha traducido en la entrega de vastos territorios indígenas en forma de concesiones de exploración y explotación a favor de grandes empresas nacionales y trasnacionales. $\mathrm{Me}$ interesa mostrar el papel protagónico que ha tenido el Estado mexicano en el posicionamiento del territorio nacional como un espacio atractivo para las grandes corporaciones, a pesar de los altos costos en materia de violación de derechos humanos colectivos y ambientales. Este escenario es el telón de fondo que permite entender las estrategias de lucha y resistencia que los pueblos indígenas, junto con otros actores sociales, están librando para detener o revertir el proceso de despojo de sus territorios y exigir el cumplimiento de sus derechos constitucionales.

Palabras clave: Autonomía, leyes mineras, extractivismo, despojos territoriales, movimientos de resistencia.
\end{abstract}

\begin{abstract}
The siege of indigenous autonomies due to the extractive mining model in Mexico. This article aims to present an overview of the impacts thas has the mine extractivism activities on the indigineous autonomies, that has been undergoing in Mexico, that has resulted in the delivery of indigenous territories in the form of exploitation and exploration concessions, in favor of large national and transnational corporations. My purpose is to show the main paper that the Mexican State has in the positioning of the country as an attractive space for the large corporations, despite the high costs in the field of human, collective and environmental rights. This setting, aloud to understand the strategies of struggle and resistance that the indigenous people, among other social actors, are waging to stop or revert the process of dispossession if their lands and to enforce their constitutional rights.
\end{abstract}

Keywords: Autonomy, Mining Laws, extractivism, territorial dispossession, resistance

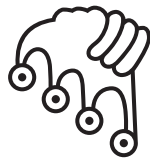

IZTAPALAPA

Agua sobre lajas

* lauravalladares.delacruz@gmail. com 
¡La tierra no se vende! ¡Se ama y se defiende!

\section{Introducción}

U no de los grandes debates nacionales y preocupaciones de vastos sectores sociales, entre ellos los pueblos indígenas, es el impacto que está teniendo el giro extractivista que desde hace más de una década forma parte de los planes de desarrollo nacional. Preocupa enormemente la instauración de áreas de enclave minero por sus consecuencias económicas, sociales, políticas y ambientales negativas, que se encaminan a la dilución o reconfiguración de la soberanía nacional, así como a la vulneración de las autonomías indígenas. Esto se debe a que las decisiones sobre los usos y formas de explotación de los recursos minerales que están asentados en los etnoterritorios son tomadas por las corporaciones mineras con la anuencia de gobierno mexicano, en campos tales como las áreas a donde se dirigen las inversiones, las formas de producir, la tecnología con que se realizan las actividades extractivas, el destino de la producción, el pago de salarios, los términos de los convenios y contratos de exploración y explotación, entre otras competencias. En este contexto llaman la atención las nimias cantidades que fiscalmente dejan las grandes corporaciones mineras al Estado mexicano, comparadas con las millonarias ganancias que obtienen y que envían a sus países de origen; situación que deja al país a merced de los intereses de las corporaciones privadas y en franca violación a los derechos de los pueblos indígenas reconocidos en la fase multiculturalista vivida en la década de los noventa del siglo pasado (Valladares, 2008), especialmente en lo referido a su derecho a la libre determinación, expresada en su derecho a ejercer la autonomía en sus territorios.

Es en este escenario que me interesa destacar las contestaciones sociales a este proceso de despojo de los territorios indígenas mostrando la envergadura del proceso, así como las estrategias de lucha que despliegan pueblos y organizaciones indígenas para detener y/o revertir el modelo extractivista minero que amenaza con destruir su patrimonio biocultural.

De sobra sabemos que el giro extractivista está basado en el despojo territorial, legitimado por una política gubernamental que, a través de la construcción de un 
marco jurídico idóneo, otorga concesiones mineras como si se tratara de espacios o territorios vacíos, violentando la autonomía de los pueblos indígenas para decidir sobre su futuro y sobre las actividades que desean emprender en sus nichos territoriales. Como corolario de este escenario se ha demostrado reiteradamente el enorme impacto negativo en la salud de los habitantes y trabajadores de las regiones mineras, sumadas a una devastación ecológica que, de acuerdo con varios especialistas, se está tornando irreversible (Boege, 2013; Toledo, 20II). Se trata de un modelo de desarrollo basado en la apropiación de la naturaleza que alimenta un entramado productivo escasamente diversificado, muy dependiente de su inserción internacional, y coloca a los países en donde se realiza como proveedores de materias primas dirigidas al mercado internacional. El giro extractivista involucra distintas actividades, por ejemplo, las energéticas, que implican exploración y explotación de petróleo, la instalación de gasoductos, la minería, preferentemente a cielo abierto, ${ }^{1}$ que es la más depredadora de los nichos ecológicos, así como la producción de monocultivos, especialmente de semillas genéticamente modificadas, entre las más relevantes (Gudynas, 2009).

Para poder dar cuenta de la envergadura y los efectos del extractivismo me centraré en el caso de las concesiones de exploración y explotación minera otorgadas en territorios de los pueblos indígenas que, como veremos, está teniendo un crecimiento acelerado, pues según los estudios realizados por Eckart Boege, la afectación impacta a por lo menos 42 de los 62 pueblos indígenas. Ha documentado que entre los años 2000 a 20I2, de las 28 millones de hectáreas identificadas como el núcleo duro de los territorios indígenas, se concesionaron alrededor de 2 I73 I4I ha, principalmente para la minería metálica. Lo cual se traduce en que en los últimos i2 años los indígenas han perdido la jurisdicción de $7 \%$ de su territorio tan solo por concesiones mineras y frecuentemente las comunidades ni siquiera están informadas (Boege, 2013). Sus pesquisas muestran que la mayoría de las concesiones en el territorio nacional fueron otorgadas al amparo de la ley minera neoliberal aprobada en 1992, durante el sexenio de Carlos Salinas de Gortari (1988-1994). Tan solo durante los años que van de 2000 al 2012 se entregaron 28 I 4 concesiones para explotar oro, 7I de plata y 25 de cobre. Sin duda, el proceso de despojo de los territorios indígenas

1 La minería a cielo abierto implica la explotación de minerales que ya no se encuentran concentrados en venas y son imposibles de extraer por minería subterránea. Los minerales dispersos con bajas concentraciones en grandes áreas requieren ahora de minería a cielo abierto. Este tipo de minería ocasiona grandes daños sobre todo a los recursos hídricos, destruye paisajes históricos y culturales laboriosamente construidos por la gente en grandes periodos. A este proceso, Garibay lo denomina construcción de una nueva geografía minera (Garibay et al., 2009). 
está avanzado en forma vertiginosa como consecuencia del boom minero. Dicho escenario fue preparado desde la década de 1990 con la política neoliberal en boga (López, 2017).

Vale la pena señalar que esta situación es compartida por gran parte del continente americano y tiene que ver con que su territorio cuenta con una gran cantidad de recursos mineros y energéticos. Por ello su explotación se ha convertido en una fuente de riqueza para los Estados nacionales latinoamericanos, tanto para los regímenes neoliberales como para los progresistas, como son los casos de Ecuador y Bolivia (Gudynas, 20II; Zibechi, 20I5), aunque como veremos en seguida, en el caso de México ni siquiera representa un gran ingreso para las arcas nacionales. Como muestra de la importancia de esta actividad hay cifras contundentes, pues la explotación minera en América Latina es la mayor del mundo, al representar 32\% del total, seguido por Oceanía con 20\%; África con I6\%; Asia con I3\%; Norteamérica con $12 \%$ y finalmente Europa con $7 \%$. A su vez, Chile, Brasil y Perú son los países que invierten más dinero en la exploración y explotación de dichos recursos (CDPI, 2OI3). De la misma manera que crecen las inversiones y los proyectos extractivos, aumentan los conflictos generados por su presencia, pues de acuerdo con el Observatorio de Conflictos Mineros en América Latina (Ocmal) existen 219 conflictos en América Latina, que involucran 229 proyectos mineros y afectan a 334 comunidades. De este escenario el país con el mayor número de conflictos es México, pues se tienen documentados 37 conflictos (Ocmal, 20I6). Sin embargo, en un estudio realizado por Sol Pérez (20I4) se informa de la existencia de IO3 conflictos, de los cuales 28 se desarrollan en territorios indígenas (Pérez, 20I4:24I) y son una muestra de las contestaciones sociales frente a la nueva geografía minera a cielo abierto (Garibay et al., 20II).

Ahora bien, si ponderamos el papel de la minería en el conjunto de las actividades económicas de México vinculadas con la Inversión Extranjera Directa (IED) tenemos que esta ha tenido un crecimiento de $8.8 \%$ anual. Durante la presente administración, la IED acumulada fue del orden de 156 194.3 millones de dólares, cifra 5I.9\% mayor al monto reportado seis años atrás. Si nos referimos ahora a los sectores en donde han llegado las inversiones, tenemos que las manufacturas representaron $49.9 \%$; los servicios financieros, $12.7 \%$; los transportes, correos y almacenamiento, II.7\%; la minería, 7.0\%; y el comercio, $6.6 \%$. Otros sectores captaron el restante I2.1\%. ( $\mathrm{SE}, 2017 \mathrm{a})$. Si bien la inversión en minería en el país parecería modesto, existe un fuerte interés por seguir ampliando este sector, como podemos constatar en el Plan de Desarrollo Minero 2013-20I8 en el cual se afirma que México tiene 75\% de su territorio con recursos minerales probados y que existe una "evolución geológica 
positiva" para considerar que esta actividad puede ampliarse, por lo que se ha establecido un plan para continuar con la entrega de concesiones a los inversionistas interesados (GR, 20I4).

En lo que concierne al aporte del sector minero al Producto Interno Bruto (PIB), este es del orden de $4 \%$, reducido en términos cuantitativos, lo que no justifica el enorme daño socioambiental y la violación de derechos humanos y colectivos que ocasiona al país. De acuerdo con los datos aportados por la Auditoria Superior de la Federación (ASF), entre 2008 y 2013 las empresas mineras dejaron a México solo $0.6 \%$ de los I.2 billones de pesos que ganaron. Sin duda, nuestro país es un paraíso de permisividad y bondad fiscal para las empresas mineras, y por ello se ha convertido en el primer destino de inversión en exploración minera en América Latina y el $4^{\circ}$ en el mundo, según el reporte publicado por SNL Metals \& Mining en 2015. Por otro lado, el reporte de la consultora Behre Dolbear, difundido también de 2015, indica que México es el $5^{\circ}$ país con el mejor ambiente para hacer negocios mineros.

Como podemos observar, si bien la minería no es el sector de mayor aporte al PIB ni ofrece un importante número de empleos, ni le genera al país mayores ganancias, sí está originando una gran cantidad de conflictos socioambientales y echando por la borda la autonomía de los pueblos indígenas, con lo que se está amenazando su supervivencia como pueblos diferenciados cultural y políticamente. Todo parece indicar que esta será la tónica de los siguientes años, pues se ha colocado a la minería como un sector estratégico para el desarrollo nacional. En este mismo sentido la ley minera vigente ( $\mathrm{SE}, 2 \mathrm{OI} 4)$ declara, en su artículo sexto, a la minería como una actividad de utilidad pública, y deja asentado que

la exploración, explotación y beneficio de los minerales o sustancias a que se refiere la ley son de utilidad pública y serán preferentes sobre cualquier otro uso o aprovechamiento del terreno con sujeción a las condiciones que establece la misma y únicamente por ley de carácter federal podrán establecerse contribuciones que graven estas actividades.

Es decir, que al declarar como de utilidad pública las actividades de exploración, explotación y beneficio de los minerales se permite la expropiación a los dueños de las tierras donde se encuentren dichos minerales, si se considerara necesaria esa medida para que se lleve a cabo la actividad minera (Bárcenas y Eslava, 20II* 17-I8). Y si bien no se han presentado casos de expropiación de territorios indígenas, sí existen abultadas concesiones mineras en sus territorios (Boege, 20I3; Pérez, 20I4), lo cual se convierte en la práctica en procesos de despojo territorial, situación que ha 
desatado un escenario de luchas de resistencia expresadas en movilizaciones sociales, así como largas y complejas disputas jurídicas en las que los pueblos apelan a sus derechos constitucionales e internacionales.

Es importante enfatizar que las luchas territoriales que protagonizan los pueblos están teniendo altísimos costos sociales, expresados en la detención o el asesinato de sus líderes, la criminalización de su justa protesta, la gestación de conflictos intracomunitarios, entre quienes ven las inversiones mineras como una oportunidad de acceder a empleos remunerados o poner pequeños negocios que respondan a las nuevas demandas de productos y servicios que arriban con los proyectos, frente a aquellos que defienden la integridad de sus territorios, su autonomía y se pronuncian en contra de la debacle ecológica. Muestra de la criminalización de los luchadores sociales es la declaración de Amnistía Internacional, la cual afirma que tan solo en los dos últimos años han sido asesinados 437 activistas pro derechos humanos en 22 países; de los cuales 75\% de los casos tuvieron lugar en América Latina y tienen que ver directamente con las actividades extractivistas (AI, 20I7). En este ambiente tan adverso, los pueblos indígenas se han sumado algunos triunfos sostenidos por vigorosos procesos organizativos, para lo cual han contado con el apoyo de organizaciones ambientalistas y defensoras de los derechos humanos y colectivos diversos. Por ello considero importante hacer un rápido recuento de los conflictos mineros más significativos en las regiones indígenas del país, recuperando las estrategias de lucha que les han permitido detener o posponer exploraciones o explotaciones en sus territorios, pero antes de ello haremos un breve recorrido por las transformaciones del Estado neoliberal que defiende este modelo extractivista.

\section{La soberanía nacional y los derechos de los pueblos indígenas en el marco del extractivismo}

Para comprender esta nueva fase del capitalismo neoliberal, David Harvey (2004) acuñó el concepto de acumulación por desposesión; con él define la forma en que la expansión del sistema capitalista se ha dirigido a la explotación de los bienes comunes que forman parte del patrimonio social de los pueblos - tierras, recursos, riquezas, derechos- a través del despojo encabezado por un determinado grupo social emplazado en una geografía específica cuyo fin es la acumulación de capital. Esto apunta a la expansión sobre los campos fronterizos de la matriz capitalista mediante el despojo, ya sea sobre ámbitos internos del capitalismo, o la privatización de bienes públicos del Estado, o bien sobre los ámbitos externos a él, como 
despojos legales o fácticos del patrimonio de uso común de las comunidades. En tal sentido, la acumulación por desposesión es el momento de la economía política propiamente dicha, de la negación de los derechos heredados, de la movilización del poder para desarticular arreglos sociales precedentes, de la imposición de un nuevo orden organizacional de lo social, del conflicto entre la matriz capitalista y los grupos sociales locales que resisten a su desposesión (Merchand, 2013).

De acuerdo con Svampa (2012), en el último decenio América Latina ha realizado el tránsito del Consenso de Washington basado en la valorización financiera, al consenso de los commodities sustentado en la exportación de bienes primarios a gran escala. Afirma con razón que si bien la exploración y exportación de bienes naturales no son actividades nuevas en la región, en los últimos años del siglo $\mathrm{xx}$ y en un contexto de cambio del modelo de acumulación se fue intensificando la expansión de proyectos tendientes al control, la extracción y la exportación de bienes naturales, sin mayor valor agregado. El Consenso de los Commodities implica subrayar, precisamente, el ingreso a un nuevo orden económico y político, sostenido por el boom de los precios internacionales de las materias primas y los bienes de consumo, demandados cada vez más por los países centrales y las potencias emergentes. El nuevo ciclo económico se caracteriza por la rentabilidad extraordinaria y altas tasas de crecimiento de las economías latinoamericanas. Para la Cepal, a pesar de la reciente inversión en la tendencia de los precios, las alzas durante la primera mitad del año 20 Io fueron tan importantes que las previsiones apuntan a que los términos del intercambio de América Latina registren una mejora importante (Svampa, 20I2).

Sin embargo, es fundamental considerar, además de la demanda creciente de materias primas en el mercado internacional, los cambios en los Estados que sostienen el modelo extractivista. Estos viraron la razón de Estado, del bien social al beneficio corporativo, a través del poder que han adquirido las grandes corporaciones privadas, que han fundido sus intereses con los gobiernos en turno en desmedro de la soberanía nacional. Por otro lado, las empresas trasnacionales se han blindado con un poder jurídico que las coloca por encima de los Estados nacionales; se trata de un nuevo derecho corporativo avalado por los tratados de libre comercio, con lo que se encuentran no solamente por encima del derecho nacional sino incluso del sistema internacional de derechos humanos, generando a su paso lo que se ha denominado "las nuevas víctimas del desarrollo" (Herreño, 2015). A esta forma de organización corporativa que impone sus intereses y somete gobiernos, organizaciones, así como a campesinos e indígenas, Claudio Garibay (2017) las denomina "clúster minero global”. Con ello se refiere, en términos fácticos, a que las empresas han suplantado al Estado y su soberanía a favor de sus intereses económicos, mientras que el Estado 
se ha transformado en un actor empresarial con intereses privados o, mejor dicho, en un duopolio, cómplice de los desastres socioambientales actuales.

En este contexto, el despojo o la amenaza de despojo de amplios territorios violenta la autonomía indígena reconocida formalmente en el artículo $2^{\circ}$ de la Constitución federal, así como en los principios del artículo I ${ }^{\circ}$ según los cuales los instrumentos internacionales en materia de derechos humanos tienen el carácter de norma nacional, en clara referencia a los derechos reconocidos en el Convenio I69 de la Organización Internacional del Trabajo (огт) signado en 1989, así como la Declaración de Derechos de los Pueblos Indígenas aprobada por la Asamblea General de la ONu en 2007 y en la Declaración Americana sobre los Derechos de los pueblos indígenas, aprobada en 2016, entre otros. En estos instrumentos se alude específicamente a los derechos culturales, políticos y territoriales de los pueblos indígenas, así como a su derecho a ser consultados previa, libre e informadamente, sobre aquellos proyectos y políticas que los puedan afectar. En lo referente a los derechos colectivos amparados en el Convenio i69 de la ort, en su apartado sobre tierras, comprendido en los artículos 13 al I9, se estipula la responsabilidad de los Estados para respetar y proteger las tierras y los territorios de los pueblos indígenas, así como sus recursos naturales. Mientras que en el artículo i5 establece que los pueblos indígenas tienen derecho a participar en la administración y conservación de dichos recursos. Y en caso de que pertenezca al Estado la propiedad de los minerales o recursos del subsuelo o tenga derechos sobre otros recursos existentes en las tierras indígenas, estos tendrán preferencia para su explotación. De tal manera que lo que está ocurriendo en la relación entre empresas-gobiernos y pueblos indígenas muestra que existen graves contradicciones entre la legislación en materia energética y minera, con respecto a los derechos indígenas; es decir, estamos ante una clara confrontación de derechos constitucionales en donde se está haciendo prevalecer los intereses privados sobre el de los pueblos. De aquí la relevancia de analizar las disputas en el campo del derecho para desentrañar la forma en que las autoridades responsables de la procuración de justicia enfrentan el reto de armonizar los derechos confrontados o sobre la forma en que hacen prevalecer unos sobre los otros.

Por estas razones, las disputas por los derechos territoriales de los pueblos indígenas se desarrollan en un nuevo escenario de pluralismo jurídico, caracterizado por el derecho construido desde arriba - el de las grandes corporaciones trasnacionales - que, basado en el principio de la lex mercatoria, garantiza sus intereses económicos. ${ }^{2}$ Un segundo corpus está conformado por los instrumentos en materia

2 La lex mercatoria se basa en mecanismos de regulación autónoma, creando un derecho 
de derechos humanos, que si bien no siempre son vinculatorios, sí representan obligaciones éticas y morales que deben cumplir los Estados y las empresas para respetar los derechos humanos de las poblaciones que se ven afectados por los megaproyectos de desarrollo. Una tercera expresión del pluralismo es el corpus del derecho del Estado mexicano que, como hemos ya señalado, por un lado reconoce derechos colectivos a los pueblos indígenas, y por otro legisla en materia energética y minera, vulnerándolos. Una cuarta dimensión del pluralismo jurídico es el del derecho indígena, construido históricamente por los pueblos indígenas, desde abajo, y que les ha permitido su continuidad como pueblos en sus nichos territoriales. Inicialmente se podría afirmar que el reconocimiento de derechos y el propio derecho indígena parecía apuntar hacia la creación de un pluralismo jurídico incipiente, en donde pudiera ser ejercido el derecho a la libre determinación en los territorios indígenas; sin embargo, con el giro extractivista todo apunta en sentido contrario. Ante esta situación, los pueblos indígenas han optado por la judialización de sus procesos de resistencia, es decir, acudir a las instancias de procuración de justicia y resolución de controversias para defender sus territorios, con lo que han logrado sumar algunos triunfos, como veremos más adelante.

Podemos afirmar que el nuevo pluralismo tiene múltiples claroscuros, pues por lo general el derecho indígena está subordinado al derecho nacional y al corporativo; sin embargo, el hecho de apelar a las diferentes instancias del poder Judicial de la federación, como son los Tribunales Agrarios, a los jueces federales o a la Suprema Corte de Justicia de la Nación en defensa de sus derechos, les ha permitido en algunos casos detener o suspender temporalmente los proyectos mineros. En otros casos las querellas son llevadas a las Naciones Unidas o a la Comisión Interamericana de Derechos Humanos.

Con intereses contrarios a los de los pueblos indígenas, las empresas acuden también a instancias nacionales a denunciar penalmente a los líderes y pobladores que protestan por su presencia, alegando que alteran la paz de sus actividades extractivas y que en algunos casos merman sus ganancias. Por otro lado, hacen uso de los paneles internacionales, construidos ad hoc para solucionar las controversias que se presentan y afectan sus intereses, y que son instancias contempladas en los tratados comerciales. ${ }^{3}$ En sus querellas se han sumado algunos triunfos, aunque

de tipo espontáneo cuya base es el principio de autonomía de la voluntad y la flexibilidad en los intercambios comerciales y las inversiones a escala internacional.

3 Tal es el caso, por ejemplo, del Centro Internacional de Arreglos y Disputas relativas a Inversiones (CIADI) del Banco Mundial (BM), en donde hasta marzo de 2013 había I69 
también han desistido de algún proyecto extractivo cuando la movilización social ha colocado el conflicto más allá del ámbito local; y en otras pocas ocasiones, las empresas han desistido de sus concesiones, cuando los conflictos, tensiones y muestras de incumplimiento o violaciones en materia ambiental o de derechos humanos han sido demostrados.

Para los pueblos, son batallas ganadas en largos y costosos procesos de lucha $y$ resistencia, pero hasta el día de hoy el conflicto de fondo sigue sin resolverse, es decir, el conflicto entre derechos confrontados. Por ejemplo, en el caso del conflicto sobre el territorio indígena de los méphaa, en la Montaña de Guerrero, los interesados han interpuesto dos amparos en contra de la declaración de libertad de sus territorios, solicitando que su territorio se declare libre de minería, a la par que se declare inconstitucional la ley minera, y si bien la jueza que revisó el último amparo tuvo la sensibilidad sobre la importancia cultural, identitaria y económica de los indígenas, así como sobre sus derechos históricos y culturales y su derecho a ser consultados en caso de cualquier proyecto que se pretenda iniciar en su territorio, y si bien dictó sentencia a favor del pueblo méphaa no abordó el asunto de la inconstitucionalidad de la ley minera, que es el tema de fondo (Sierra, en prensa).

En este sendero podemos constatar que uno de los rostros visibles de este nuevo pluralismo jurídico son los cambios en los propios Estados nacionales que están retornando a modelos intolerantes y represores en aras de garantizar los intereses de las grandes corporaciones internacionales. Ahora el Estado tiene un nuevo rostro: es un medio de control en términos de Wacquant (2009) y de la "seguridización" como política pública (Gledhill, 2014). En opinión de Giorgio Agamben (2016), vivimos en un Estado de emergencia que se inscribe en un proceso que está haciendo evolucionar las democracias occidentales hacia algo que hay que llamar Estado de seguridad, es decir, que las razones de seguridad han tomado el lugar de aquello que se llamaba en otro tiempo la razón de Estado. En el Estado de seguridad, este esquema se invierte: el Estado se funda duraderamente en el miedo y debe, a toda costa, mantenerlo, pues extrae de él su función esencial y su legitimidad. Esto ha sido documentado en múltiples casos en que se ha criminalizado la justa protesta social de todos aquellos actores sociales que se oponen a esta nueva fase de desposesión. Por estas condiciones se ha calificado también a los "Estados como fallidos" caracterizados por una "desviación del poder", noción que alude a la forma de actuación de los Estados que protagonizan violaciones graves de derechos humanos,

casos de disputas entre inversionistas contra Estados, de los cuales, 60 se relacionan con disputas por petróleo, minería o gas. 
especialmente después de la celebración de múltiples tratados de libre comercio y reformas constitucionales que favorecen la puesta en marcha del extractivismo como alternativa para el denominado eufemísticamente "desarrollo". Por estas razones, las repercusiones de un Estado fallido impactan no solo en el ámbito del poder Ejecutivo, sino también en los poderes Legislativo y Judicial. Una formulación de esta naturaleza permite dar seguimiento al patrón de continuidad en la utilización de las instituciones fundamentales del Estado para fines distintos de aquellos para los que fueron creadas. El Estado se convierte en un enemigo de la justicia y promotor de las racializaciones y la criminalización de la justa protesta (TPP, 20I4). Así, parecería que el rol del Estado es mantener el orden económico y disuadir a los críticos en esta fase del capitalismo salvaje para garantizar su reproducción; sin embargo, pueblos, comunidades, autoridades indígenas, ambientalistas, abogados, organizaciones sociales no cejan en su esfuerzo por detener esta fase del capitalismo, como veremos en el siguiente apartado.

\section{Resistencias al extractivismo: articulaciones y desarticulacio- nes locales y globales}

Las luchas en defensa de los territorios indígenas se han multiplicado tanto como los intentos o procesos de despojo territorial a lo largo y ancho del país. De acuerdo con los datos aportados en la investigación de la geógrafa Sol Pérez (2014) hay 29 conflictos que afectan a 11 diferentes etnias localizadas en distintos estados de la república, lo que representa $28 \%$ del total de conflictos existentes, que se elevan a II3. Otro de los datos significativos es que en solo i2 de los conflictos no se registró ningún tipo de violencia, mientras que en 58 se había reportado la militarización de las comunidades (Pérez, 2014: 238-239). Lo que nos muestra la delicada situación que viven los pueblos y comunidades que osan desafiar el poder de las grandes corporaciones mineras y de las autoridades que las protegen (véase cuadro I).

\section{Cuadro i.}

Conflictos mineros en territorios indígenas

\begin{tabular}{llc}
\hline Etnia & Entidad & Conflictos \\
\hline Náhuatl & Colima, Michoacán & 13 \\
\hline Rarámuri (tarahumara) & Chihuahua & 4 \\
\hline Tlapaneca, mixteca, amuzga & Guerrero & 3 \\
\hline
\end{tabular}




\begin{tabular}{lll}
\hline Wirrárika (huichol) & Jalisco, Nayarit & 2 \\
\hline Otomí chichimeca & Querétaro & 2 \\
\hline Totonaca & Veracruz & 2 \\
\hline Zapoteca, chatina y mixteca & Oaxaca & 2 \\
\hline Zapoteca & Oaxaca & I \\
\hline Total & & 29 \\
\hline
\end{tabular}

Fuente: Pérez, 2014:240.

En cuanto al panorama de la conflictividad provocada por el arribo de las empresas mineras a los territorios indígenas podemos señalar que existe un patrón común de estrategias de defensa que va desde los pronunciamientos públicos sobre su rechazo a los denominados "proyectos de muerte", las declaratorias de sus territorios como libres de minería, pasando por las protestas públicas en asambleas comunitarias o públicas, hasta los bloqueos de carreteras o a la entrada de las minas, acompañados de mítines ante las autoridades locales, estatales y federales. Además, han acudido a los congresos estatales o al Congreso de la Unión en la Ciudad de México, para exigir a los diputados que intervengan para detener el desastre ecológico que provoca la minería, así como para que se revise la legislación en materia energética y minera de forma que no vulneren sus derechos constitucionales. Estos actores han acudido reiteradamente a las comisiones de derechos humanos buscando detener los despojos, así como para denunciar las persecuciones de que son objeto los activistas contra el extractivismo y exigir justicia para los criminalizados, los presos y asesinados a lo largo de esta costosa lucha por la autonomía de los pueblos indígenas sobre sus territorios.

Como parte de sus acciones de resistencia se han aliado y asesorado por abogados democráticos, ambientalistas, académicos, defensores de derechos humanos, organizaciones de la sociedad civil, entre otros. Es notoria su participación en las redes nacionales e internacionales que se han constituido como fuertes opositores a los megaproyectos extractivistas, tales como la Red Mexicana de Afectados por la Minería (REMA), el Movimiento Mesoamericano contra el Modelo Extractivo Minero (M4), El Movimiento Mexicano de Afectados por las Presas y Defensa de los Ríos (Mapder), la Coalición de Organizaciones Mexicanas por el Derecho al Agua (Comda) y la Asamblea Nacional de Afectados Ambientales (ANAA), entre las más significativas.

Otra de las vertientes importantes en los procesos de lucha para detener los despojos territoriales ha sido recurrir a las instancias de procuración de justicia. En 
este camino han acudido a instancias internacionales como la Comisión Interamericana de Derechos Humanos e incluso a la embajada canadiense, a denunciar las constantes violaciones de derechos que encabezan las empresas que proceden de ese país. Es decir, en la última década varios pueblos se han opuesto férreamente al saqueo de sus territorios y se han sumado algunos triunfos, pocos, pero significativos, pues alientan a otros pueblos afectados a organizarse e informarse sobre los efectos a corto, mediano y largo plazo del extractivismo minero. Tales son los casos de los wirrárika en Jalisco; los nahuas del municipio de Chicomuselo, Chiapas; los nahuas de Zacualpan, Colima; los méphaa de la Montaña de Guerrero; o los zapotecos de San José del Progreso, en Oaxaca, entre los más significativos.

Si bien podemos señalar que las estrategias señaladas anteriormente se presentan en muchos de los procesos de lucha contra el extractivismo, cada conflicto tiene particularidades que obedecen a la forma en que los pueblos entran en contacto y se relacionan con las empresas mineras. Las estrategias y la envergadura del conflicto responden también al estado de la actividad minera, es decir, en algunas ocasiones el conflicto se activa en cuanto los pueblos tienen conocimiento de que su territorio o una porción de él ha sido considerada como disponible para ser concesionado al mejor postor (wirrárika, méphaa). En otros casos los disensos se expresan cuando los pueblos conocen a los detentadores de concesiones porque llegan personas ajenas a sus tierras a realizar actividades de prospección. También, hay experiencias de disenso cuando los representantes de alguna empresa arriban a los poblados para proponer acuerdos de arrendamiento de sus terrenos y a fijar su pago (campesinos de Chicomuselo). En ocasiones, aun después de haber firmado contratos "de común acuerdo", al poco tiempo se generan descontentos por parte de comuneros, ejidatarios y campesinos, algunas veces por el incumplimiento de los términos del contrato, o por la falta de entrega de los apoyos o las obras comprometidas a favor de las comunidades implicadas, o por los impactos sobre sus recursos hidráulicos o agrícolas (nahuas de Zacualpan, rarámuri, de Chihuahua o los zapotecos de San Mateo Calpulalpan, Oaxaca) (véase cuadro 2).

En el caso, por ejemplo, de los rarámuri en Chihuahua, en cuyo territorio existen cerca de 60 proyectos mineros, la mayor parte de ellos bajo el sistema de tajo abierto, ${ }^{4}$ cuyo avance ha ido generando conflictos y tensiones entre los ejidatarios que firmaron contratos de arrendamiento de sus tierras a favor de diversas empresas, los conflictos se han ido multiplicando por la inconformidad en cuanto al pago por

4 Los cuales, por cierto, fueron anunciados con bombo y platillo por el gobernador del estado desde hace tres años (García, 20I4). 
las tierras, o por los bajos salarios, o por los daños ecológicos. Han confrontado que los costos ambientales y sociales negativos los están asumiendo ellos. Tal es el caso de conflictos en donde operan minas como Minefinders Corporation Limited, "Minera Dolores", Glamis Gold, Mine Finders, entre otras (Breach, 2008).

En seguida menciono los principales conflictos que involucran a diferentes pueblos indígenas (cuadro 2). Algunos conflictos tienen ya varios años de presentarse. En el menor número de casos han concluido con una resolución judicial a su favor, pero otros siguen su curso. No es un listado exhaustivo en virtud de que el mapeo y la documentación de conflictos no es sencillo de seguir, tanto por su emplazamiento a lo largo y ancho del territorio nacional, como porque son noticia en los medios de comunicación nacional solo cuando el conflicto ha escalado niveles de violencia que son ya difíciles de ocultar. Sobre esto último es importante rescatar la atinada y comprometida labor realizada por OCMAL, la REMA o el M4, y por organizaciones no gubernamentales que acompañan y realizan actividades de defensoría de los procesos en disputa; aquí podemos mencionar al Centro de Derechos Humanos de la Montaña Tlachinollan, de Guerrero, entre otras muchas organizaciones. Otra fuente de información muy rica son los trabajos de investigación que se realizan en diferentes universidades y centros de investigación. Y si bien existe un abundantísimo cúmulo de información y análisis serios y bien documentados sobre los daños y conflictos que genera el modelo extractivo, el gobierno nacional continúa avalando lo que parece un avance imparable.

\section{Cuadro 2.}

Pueblos indigenas que registran conflictos por proyectos mineros

\begin{tabular}{|c|c|c|c|}
\hline $\begin{array}{l}\text { Pueblo } \\
\text { Indigena }\end{array}$ & $\begin{array}{l}\text { Entidad: } \\
\text { municipio }\end{array}$ & Mina/Empresa & Desarrollo del conflicto \\
\hline $\begin{array}{l}\text { Nahua y } \\
\text { totonaco }\end{array}$ & $\begin{array}{l}\text { Puebla: Tetela de } \\
\text { Ocampo, Zautla, } \\
\text { Olintla }\end{array}$ & $\begin{array}{l}\text { Proyecto Tetela: } \\
\text { Industrias Peñoles }\end{array}$ & $\begin{array}{l}\text { Protestas por la contaminación pro- } \\
\text { vocada por el derrame de cianuro. }\end{array}$ \\
\hline Wirrárika & $\begin{array}{l}\text { San Luis Potosí: } \\
\text { Wirikuta }\end{array}$ & $\begin{array}{l}\text { Fight Transnational } \\
\text { Mining }\end{array}$ & $\begin{array}{l}\text { 2003. Formación del Frente Amplio } \\
\text { de Oposición a la Minería. Minería } \\
\text { a cielo abierto. Cerro San Pedro y } \\
\text { Catorce. } I^{\circ} \text { Pueblo fantasma. Viola- } \\
\text { ción al derecho a la consulta. Inter- } \\
\text { posición de amparos. }\end{array}$ \\
\hline Wirrárika & $\begin{array}{l}\text { Jalisco, Nayarit y } \\
\text { Durango }\end{array}$ & $\begin{array}{l}\text { First Majestic Silver } \\
\text { Corp. (Canadá, } 22 \\
\text { concesiones) }\end{array}$ & $\begin{array}{l}\text { 2010. Crearon, con apoyo de organi- } \\
\text { zaciones civiles y culturales, el Frente } \\
\text { de Defensa de Wirikuta Tamatsima }\end{array}$ \\
\hline
\end{tabular}




\begin{tabular}{|c|c|c|c|}
\hline $\begin{array}{l}\text { Pueblo } \\
\text { Indigena }\end{array}$ & $\begin{array}{l}\text { Entidad: } \\
\text { municipio }\end{array}$ & Mina/Empresa & Desarrollo del conflicto \\
\hline & & & $\begin{array}{l}\text { Wahaa (el agua de nuestro hermano } \\
\text { mayor). Realizaron gestiones admi- } \\
\text { nistrativas, políticas, amplia difu- } \\
\text { sión en todos los medios posibles en } \\
\text { defensa de su territorio y sus sitios } \\
\text { sagrados. Llevaron su protesta a foros } \\
\text { internacionales. } \\
20 \text { II. Interponen amparo que se } \\
\text { resolvió a su favor. }\end{array}$ \\
\hline Wirrárika & Nayarit: La Yesca & $\begin{array}{l}\text { US Resources LTD } \\
\text { First Majestic Silver } \\
(22 \text { concesiones que } \\
\text { abarcan } 6327 \text { ha del } \\
\text { Área Natural Prote- } \\
\text { gida y Sitio Sagrado } \\
\text { Natural de Wirikuta) }\end{array}$ & $\begin{array}{l}\text { Crearon el Frente Amplio contra la } \\
\text { minería en su territorio. Interposi- } \\
\text { ción de amparos. Están vigentes } 201 \\
\text { concesiones en la entidad. }\end{array}$ \\
\hline $\begin{array}{l}\text { Méphaa, } \\
\text { mixtecos } \\
\text { (nuú savi) } \\
\text { nahuas }\end{array}$ & $\begin{array}{l}\text { Guerrero: Costa y } \\
\text { Montaña }\end{array}$ & $\begin{array}{l}\text { Gold Corp, Barrick } \\
\text { Renco Group, entre } \\
\text { otras }\end{array}$ & $\begin{array}{l}2005-2010 \text {. Se entregaron } 200000 \\
\text { ha en concesión a diversas empresas. } \\
\text { Lucha contra concesiones y declara- } \\
\text { ción de libertad de territorio. }\end{array}$ \\
\hline Méphaa & $\begin{array}{l}\text { Guerrero: San } \\
\text { Miguel del } \\
\text { Progreso (Júba } \\
\text { Waj'ín }\end{array}$ & $\begin{array}{l}\text { Corazón de las } \\
\text { tinieblas }\end{array}$ & $\begin{array}{l}\text { 20II. Lucha contra concesiones, con- } \\
\text { tra mina de plata, Ier. amparo a su } \\
\text { favor } 2013 \text {. Segundo amparo ganado, } \\
\text { 20I7, Organizaciones articuladoras } \\
\text { de las resistencia: CRAC-ONG Tla- } \\
\text { chinollan. }\end{array}$ \\
\hline Zapoteco & Oaxaca & $\begin{array}{l}\text { Magdalena Teitipac } \\
\text { Linear Gold Corpo- } \\
\text { ration }\end{array}$ & $\begin{array}{l}\text { Contaminación de mantos freáticos. } \\
\text { Desconocieron al presidente del } \\
\text { Comisariado de Bienes Comunales, } \\
\text { por confabular con la empresa. }\end{array}$ \\
\hline Zapoteco & $\begin{array}{l}\text { Oaxaca: San } \\
\text { Mateo Calpu- } \\
\text { lalpan }\end{array}$ & $\begin{array}{l}\text { Asarco-Continuum } \\
\text { Resources } \\
\text { Compañía Minera la } \\
\text { Natividad y Anexas } \\
\text { Sundance Minerals }\end{array}$ & $\begin{array}{l}\text { 2005. Solicitan a la Profepa realizar } \\
\text { revisión ambiental por actividades } \\
\text { mineras. Logran suspensión y clau- } \\
\text { sura temporal de la mina por un año. } \\
\text { 20Io. Reinicio de la explotación. } \\
20 \text { II. Rechazo de la Asamblea } \\
\text { Comunitaria a la minería, multa a la } \\
\text { empresa por un millón de pesos por } \\
\text { daño ambiental (agua, tierra y aire), } \\
\text { logran la clausura temporal. Movili- } \\
\text { zación aglutinada en el Tercer Foro }\end{array}$ \\
\hline
\end{tabular}




\begin{tabular}{|c|c|c|c|}
\hline $\begin{array}{l}\text { Pueblo } \\
\text { Indigena }\end{array}$ & $\begin{array}{l}\text { Entidad: } \\
\text { municipio }\end{array}$ & Mina/Empresa & Desarrollo del conflicto \\
\hline & & & $\begin{array}{l}\text { Nacional "Tejiendo la resistencia en } \\
\text { defensa de nuestros territorios". }\end{array}$ \\
\hline Zapoteco & Oaxaca: Zaniza & $\begin{array}{l}\text { Altos Hornos de } \\
\text { México }\end{array}$ & $\begin{array}{l}\text { 1997. Grupo Acerero del Norte, hoy } \\
\text { Altos Hornos, obtuvo concesión con } \\
\text { anuencia de las autoridades muni- } \\
\text { cipales y agrarias para estudios de } \\
\text { exploración. Por daños ecológicos en } \\
\text { I999, las autoridades, con el acuerdo } \\
\text { de la Asamblea General, suspenden } \\
\text { el permiso. } \\
\text { 20I3. Refrendan su rechazo a la } \\
\text { minería. }\end{array}$ \\
\hline Zapoteco & $\begin{array}{l}\text { Oaxaca: San José } \\
\text { del Progreso, } \\
\text { Ocotlán }\end{array}$ & $\begin{array}{l}\text { Fortuna Silver (3I } \\
\text { concesiones) } \\
\text { Otras empresas } \\
\text { trabajan en la zona }\end{array}$ & $\begin{array}{l}\text { Compraron tierra a los ejidatarios. } \\
\text { 2008. Los ejidatarios constituyen la Coor- } \\
\text { dinadora de Pueblos Unidos del Valle de } \\
\text { Ocotlán (Cpuvo), obligan a renunciar al } \\
\text { comisariado de bienes ejidales. } \\
\text { 2009. Toman las instalaciones de } \\
\text { la minera Cuzcatlán, solicitan a la } \\
\text { Semarnat cancele el proyecto por } \\
\text { daño ambiental. } \\
\text { 20I2. El presidente municipal y un } \\
\text { síndico agreden con armas de fuego } \\
\text { a los opositores a la mina. }\end{array}$ \\
\hline Mixteco & $\begin{array}{l}\text { Oaxaca: Mixteca } \\
\text { Alta Silacayopilla }\end{array}$ & $\begin{array}{l}\text { Miriam / Arco } \\
\text { Resources Corpo- } \\
\text { ration }\end{array}$ & $\begin{array}{l}\text { 20I2. La asamblea comunitaria } \\
\text { rechaza la concesión minera porque } \\
\text { vulnera sus derechos autonómicos. }\end{array}$ \\
\hline Nahuas & $\begin{array}{l}\text { Puebla: } \\
\text { Ixtacamaxtitlán }\end{array}$ & $\begin{array}{l}\text { Tuligtic / Almaden } \\
\text { Minerals }\end{array}$ & $\begin{array}{l}\text { 2013. Se oponen a la explotación a } \\
\text { cielo abierto. }\end{array}$ \\
\hline Nahuas & $\begin{array}{l}\text { Puebla: } \\
\text { Zacapoaxtla }\end{array}$ & Varios proyectos & Oposición a mineras en su territorio. \\
\hline Nahuas & Puebla: Zautla & $\begin{array}{l}\text { La Lupe / JDC Mine- } \\
\text { rals (China) }\end{array}$ & $\begin{array}{l}2012.5 \text { ooo habitantes de } 32 \text { comu- } \\
\text { nidades clausuraron la mina y die- } \\
\text { ron ultimátum de } 24 \text { horas para que } \\
\text { empleados y ejecutivos abandonen } \\
\text { las oficinas que tienen en la comuni- } \\
\text { dad de Tlamanca. Se logró detener } \\
\text { la explotación. }\end{array}$ \\
\hline Nahuas & $\begin{array}{l}\text { Jalisco: ejido } \\
\text { Ayotitlán }\end{array}$ & $\begin{array}{l}\text { Gran-Bo, Gran Bo } \\
\text { Internacional (China) }\end{array}$ & $\begin{array}{l}\text { 2007. Invasión del predio agrícola } \\
\text { Lino Roblada, para explotar oro, }\end{array}$ \\
\hline
\end{tabular}




\begin{tabular}{|c|c|c|c|}
\hline $\begin{array}{l}\text { Pueblo } \\
\text { Indigena }\end{array}$ & $\begin{array}{l}\text { Entidad: } \\
\text { municipio }\end{array}$ & Mina/Empresa & Desarrollo del conflicto \\
\hline & & & $\begin{array}{l}\text { plata y hierro; los indígenas retienen } \\
\text { maquinaria y la empresa se desiste, } \\
\text { pero realiza nuevas exploraciones en } \\
\text { predios cercanos. } \\
\text { 2013. La comunidad agraria de } \\
\text { Tequesquitlán, del municipio de } \\
\text { Cuautitlán, lograron un amparo que } \\
\text { ordena a la Semarnat dejar insub- } \\
\text { sistente la autorización de impacto } \\
\text { ambiental y cambio de uso de suelo } \\
\text { forestal para la primera fase de } \\
\text { explotación del predio el Ratón, y } \\
\text { que ajuste su decisión a las normas } \\
\text { constitucionales. }\end{array}$ \\
\hline Nahuas & $\begin{array}{l}\text { Jalisco: } \\
\text { Cuautitlán } \\
\text { Nayarit: comu- } \\
\text { nidad indígena y } \\
\text { ejido Ayotitlán }\end{array}$ & $\begin{array}{l}\text { Manatlán, mineras } \\
\text { ilegales }\end{array}$ & $\begin{array}{l}\text { 20I2. Dos minas operan sin permiso } \\
\text { de la comunidad ni de Semarnat, } \\
\text { Conagua y Profepa. Logran la can- } \\
\text { celación de las concesiones. }\end{array}$ \\
\hline Nahuas & $\begin{array}{l}\text { Michoacán: } \\
\text { Aquila }\end{array}$ & $\begin{array}{l}\text { Ternium / Arcelor } \\
\text { Mittal Steel Com- } \\
\text { pany N.V. }\end{array}$ & $\begin{array}{l}\text { 20II. Indígenas demandan a la } \\
\text { empresa italo-argentina pago por la } \\
\text { renta de sus terrenos donde extraen } \\
\text { hierro. Comuneros desconocen el } \\
\text { acuerdo con la empresa porque no los } \\
\text { beneficia. Formaron grupo de auto- } \\
\text { defensa contra crimen organizado. }\end{array}$ \\
\hline Nahuas & $\begin{array}{l}\text { Colima: Comala, } \\
\text { comunidad de } \\
\text { Zacualpan }\end{array}$ & Gabner sA de cv & $\begin{array}{l}\text { 20I3. Vigorosa organización y movi- } \\
\text { lización en contra de la instalación } \\
\text { de las minas, destituyen a su comi- } \\
\text { sario de bienes comunales e inician } \\
\text { una lucha en el Tribunal Agrario. Se } \\
\text { declaran territorio libre de minería } \\
\text { en mayo de } 2014 \text {. }\end{array}$ \\
\hline $\begin{array}{l}\text { Otomí-chi- } \\
\text { chimeca }\end{array}$ & $\begin{array}{l}\text { Querétaro: } \\
\text { Tolimán }\end{array}$ & $\begin{array}{l}\text { Unites States Anti- } \\
\text { mony Corporation }\end{array}$ & $\begin{array}{l}\text { 20II. Los indígenas bloquean los } \\
\text { accesos a la planta de producción de } \\
\text { antimonio en la comunidad de San } \\
\text { Antonio de la Sal, la compañía dejó } \\
\text { de hacer pruebas de instalación, des- } \\
\text { manteló las instalaciones y evacuó el } \\
\text { predio. }\end{array}$ \\
\hline
\end{tabular}




\begin{tabular}{|c|c|c|c|}
\hline $\begin{array}{l}\text { Pueblo } \\
\text { Indigena }\end{array}$ & $\begin{array}{l}\text { Entidad: } \\
\text { municipio }\end{array}$ & Mina/Empresa & Desarrollo del conflicto \\
\hline $\begin{array}{l}\text { Mam, tsotsil, } \\
\text { tseltal, }\end{array}$ & $\begin{array}{l}\text { Chiapas: Soco- } \\
\text { nusco }\end{array}$ & Varias & $\begin{array}{l}\text { 20I3. Se crean grupos de autodefensa } \\
\text { contra la minería tóxica. Decenas de } \\
\text { comunidades se declaran libres de } \\
\text { minería en sus Asambleas Comu- } \\
\text { nitarias. Exigen la cancelación de } \\
\text { concesiones. }\end{array}$ \\
\hline Zoques & $\begin{array}{l}\text { Chiapas: Ixhua- } \\
\text { tán }\end{array}$ & $\begin{array}{l}\text { Linear Gold Cor- } \\
\text { poration (incluye a } \\
\text { varias empresas) }\end{array}$ & $\begin{array}{l}\text { 2003. Se proyecta corredor minero en } \\
\text { los municipios de Pichucalco, Ostua- } \\
\text { cán, Tecpatán hasta Tapalapa, que } \\
\text { afectarían la tierra de I } 8 \text { municipios } \\
\text { zoques sin ser consultados. } \\
\text { 2009. Por las protestas y presión } \\
\text { social, la empresa canceló sus ope- } \\
\text { raciones. }\end{array}$ \\
\hline Rarámuri & $\begin{array}{l}\text { Chihuahua: } \\
\text { Madera }\end{array}$ & $\begin{array}{l}\text { Minefinders Corpo- } \\
\text { ration Ltd."Minera } \\
\text { Dolores", Glamis } \\
\text { Gold, Mine Finders, } \\
\text { entre otras }\end{array}$ & $\begin{array}{l}\text { 20I4. Inicia la construcción del com- } \\
\text { plejo minero en la sierra. } \\
\text { 20I6. Sesenta proyectos para nuevas } \\
\text { minas a cielo abierto. En distintos } \\
\text { ejidos. En el ejido Palmarejo, muni- } \\
\text { cipio de Chínipas y en el municipio } \\
\text { de Madera existen conflictos con } \\
\text { las empresas. Aprueban de forma } \\
\text { corrupta la firma de convenios de } \\
\text { arrendamiento de tierras en ejidos. }\end{array}$ \\
\hline
\end{tabular}

Fuente: Elaboración propia con base en Matías, 2015; Breach, 2018; Pérez, 2017; López, 2017; Castro, 2012; García, 2014; Tlachinollan, 2016; Valladares, en prensa.

Entre los procesos de lucha y resistencia indígena podemos señalar algunos que ilustran el escenario y las estrategias de defensa de los pueblos por sus territorios indígenas. Por ejemplo, en agosto de 2013, en el marco del Día Internacional de los Pueblos Indígenas, zapotecos, chontales, mixtecos, chinantecos, ikoots y mixes acordaron prohibir en sus territorios proyectos mineros, eólicos, hidráulicos y la siembra de maíces transgénicos, así como dejar de pagar por servicios ambientales e hidrológicos, áreas naturales protegidas y de conservación comunitaria. Denunciaron que las instituciones estatales están fuertemente ligadas a los intereses empresariales, por lo que su visión de desarrollo no corresponde ni representa las aspiraciones de los pueblos originarios. Por tal motivo, hicieron llegar una carta abierta al presidente Enrique Peña Nieto y al entonces gobernador del estado de Oaxaca, Gabino Cué Monteagudo, firmada por 33 comunidades y pueblos indígenas, junto con Io 
organizaciones civiles. Denunciaron que "la política actual del gobierno mexicano atenta gravemente contra nuestros derechos como pueblos indígenas, campesinos y rurales". Afirmaron que el territorio no es una mercancía y que en esta fecha "no festejamos, denunciamos". También se quejaron de que diversos funcionarios públicos han utilizado el chantaje y condicionado la entrega de programas públicos como Procampo, Oportunidades, 70 y más, entre otros, valiéndose de su pobreza económica para obtener la respuesta favorable de algunas autoridades (Matías, 2015). En la misma entidad, los zapotecos, a través de sus autoridades ejidales y comunales de los distritos de Ejutla, Ocotlán y Tlacolula, en voz del representante del Colectivo en Defensa de los Territorios, declararon igualmente sus territorios libres de minería. La declaratoria fue firmada por nueve autoridades de Valles Centrales, en la que exigen al gobierno federal y estatal la cancelación de i8 proyectos mineros. El documento fue entregado a las secretarías de Gobernación, de Economía y del Medio Ambiente, así como a la CNDH, además de instancias estatales de Turismo y Desarrollo Económico, Defensoría de los Derechos Humanos del Pueblo de Oaxaca y a la Secretaría de Asuntos Indígenas (Matías, 2015).

Existen otro tipo de distorsiones: desde que la entrega de programas y recursos no provienen de las autoridades estatales o son muy reducidos, las empresas han tomado su lugar con miras a obtener la firma de convenios de arrendamiento en las tierras y territorios de campesinos e indígenas. De esta forma buscan construir una imagen positiva de las empresas, asumiéndose como "comprometidas o responsables socialmente" con lo que, de paso, buscan construirse una legitimidad o una aceptación que evite protestas durante su estancia en las zonas en que operan. Construyen caminos, pintan escuelas, apoyan las celebraciones tradicionales, donan sillas de ruedas, prometen construir obras para el acceso al agua potable, entre otras actividades. Con ello buscan crear una imagen positiva, lo que sin duda alguna es una perversión de la realidad, un eufemismo, por decir lo menos.

Entre los pueblos indígenas que también han declarado sus territorios libres de megaproyectos, están los pueblos nahuas y totonacos de la Sierra Norte de Puebla y la región de Totonacapan, Veracruz, en donde más de 5000 indígenas de 25 municipios se reunieron en asamblea, el 5 de febrero de 2016, para hacer tal declaración en contra de los proyectos mineros, petroleros e hidroeléctricos (Regeneración, 2016). Por su parte, los campesinos e indígenas representantes agrarios y comunitarios de la Montaña Alta y Costa Chica de Guerrero declararon un año antes su territorio como libre de minería; con ello exigieron la cancelación inmediata de todas las concesiones que han sido entregadas en esa región y rechazaron la creación de una Reserva de la Biosfera. En esta zona los indígenas méphaa, na savi y nahuas denunciaron que 
el Registro Agrario Nacional solamente les aceptó el registro de tres actas de las comunidades que documentan la decisión tomada; afirmaron que "al darse cuenta de que ya somos mayoría", las rechazaron por supuestos defectos de forma y fondo. Denunciaron con ello otra de las realidades que se presentan en algunos conflictos, que alude a la corrupción de las autoridades agrarias o políticas tanto de sus propias comunidades como las estatales. En el caso de la Montaña de Guerrero, señalaron que los representantes del Registro Agrario Nacional (RAN) violentaron su derecho a la consulta previa, libre e informada, "además de violentar la ley agraria" al negarse a inscribir nuestras actas de asambleas, donde hemos ratificado el "no a la minería en nuestras tierras" (Regeneración, 2016). ${ }^{5}$ Por esta circunstancia, los indígenas y campesinos decidieron formar el Consejo Regional de Autoridades Agrarias por la Defensa del Territorio y en Contra de la Minería y de la Reserva de la Biosfera en la Montaña y Costa Chica de Guerrero, a través del cual insistieron en que los pueblos deben ser consultados respecto a las concesiones mineras apegándose al Convenio I69 de ort, y señalaron que sus decisiones están basadas no solo en este convenio, sino en la Ley 7or del Estado de Guerrero y en la Declaración sobre los Derechos de los Pueblos Indígenas de las Naciones Unidas (Serapaz, 2015).

Recordemos que algunas disputas son llevadas al campo de la procuración de justicia: inician juicios agrarios y de amparo; los primeros para anular contratos de arrendamiento por leoninos o por el incumplimiento de algunas de las cláusulas en ellos contenidos; los segundos por violaciones a sus derechos, como la falta de consulta previa, libre e informada, antes de otorgar concesiones para explotar los recursos naturales existentes en sus territorios o permisos para la realización de diversos tipos de obras (López, 2017: 18). En este sendero, por ejemplo, hay varios casos. El I7 de marzo de 2015, el pueblo macehual que habita los municipios de Cuetzalan, Tlatlauquitepec y Yahonahuac, en el estado de Puebla, interpusieron un amparo que fue admitido en el Juzgado Segundo de Distrito con sede en la ciudad de Puebla. Por su parte, el pueblo náhuatl de la comunidad de Zacualpan, en Colima, hizo lo propio ingresando su demanda el 24 de marzo del mismo año, la cual fue admitida por el Juzgado Primero de Distrito con sede en la ciudad de

Una situación semejante tuvieron que enfrentar los nahuas de Zacualpan, cuando la representante de la Procuraduría Agraria de Colima se negaba a registrar su acta de Asamblea; esto no se logró hasta que los comuneros destituyeron a su representante, se movilizaron y protestaron ampliamente, lo que llevó al asesinato de su líder Mariano Abarca, así como a la persecución de sus aliados y asesores de la organización Bio Iguana, quienes los acompañaron en su lucha contra la minera Gabner sA de cv durante los años 2013 a 2015 en que se desarrolló el conflicto. 
Colima. Este ciclo de amparos presentados en 2015 lo cerró la comunidad campesina de Tecoltemic, ubicada en el municipio de Ixtacamaxtitlán, Puebla, la cual presentó su demanda el 7 de abril, siendo admitida por el Juzgado Cuarto de Distrito con sede en la ciudad de Puebla. Los tres juicios de amparo fueron admitidos por el poder Judicial de la federación, otorgando la suspensión de las concesiones mineras a favor de los pueblos originarios. Este es un hecho de suma importancia, pues significa que mientras duren los trámites de los juicios de amparo, las compañías que detentan las concesiones mineras no podrán realizar actividades tendientes a la explotación (López, 20I7).

A mi parecer, López Bárcenas (2017: 15) sintetiza de forma muy clara el significado que tiene para los pueblos indígenas la defensa de sus tierras y territorios en la consigna cientos de veces enarbolada: ¡La tierra no se vende! ${ }_{¡}$ Se ama y se defiende!, afirma que

es una consigna que encontró su razón de ser en la férrea oposición de las comunidades campesinas, pueblos indígenas y sectores populares a esas políticas privatizadoras del régimen. Pero es algo más que eso. También refleja la visión que las comunidades campesinas y los pueblos indígenas tienen de la tierra y su voluntad de seguirla manteniendo. Con ella nos dicen que, para ellos, la tierra no es una mercancía que pueda venderse al mejor postor, sino su madre, la que les dio la vida, a la que tienen que mantener como ella los mantiene a ellos; a la que tienen que cuidar para que esté sana porque de su salud depende la de ellos; de la que salieron y a la que algún día tendrán que volver. Afirma que cada vez que lanzan la consigna nos dicen que ellos no explotan irracionalmente la tierra y sus recursos naturales, usan los que necesitan para satisfacer sus necesidades, pues bien saben que la tierra no les pertenece, son ellos los que pertenecen a ella. Esa es la razón por la que reclaman que se le valore como el lugar de donde se obtienen los alimentos que consumimos, el agua que tomamos, el oxígeno que respiramos, el paisaje que disfrutamos, en fin, la cultura que nos identifica (López, 2017).

Quisiera terminar este texto señalando que el debate sobre el extractivismo ha sido muy intenso a lo largo de las dos últimas décadas, la oposición ha estado encabezada por los pueblos, comunidades, autoridades, activistas, ambientalistas, académicos, organizaciones no gubernamentales, e incluso algunos políticos, pero los enemigos son muy poderosos, pues si pensamos en términos cuantitativos no pasan de una decena los casos en que los pueblos y comunidades han logrado detener algún proyecto minero, pero se constituyen como un referente que alienta otros procesos 
de resistencia y muestran la necesidad no solo de detener estos proyectos, sino reflexionar sobre los rumbos que está tomando el capitalismo contemporáneo, pero no bastan las alertas pues, como ha señalado Boaventura de Souza Santos, estamos ante un pensamiento anacrónico inverso, pues

Vivimos una dictadura informal con imaginarios de democracia formal; vivimos un tiempo de cuerpos racializados, sexualizados, asesinados, descuartizados con imaginarios de derechos humanos; vivimos un tiempo de muros, fronteras como trincheras, exilios forzados, desplazamientos internos con imaginarios de globalización; vivimos un tiempo de silenciamientos y de sociología de las ausencias con imaginarios de orgía comunicacional digital; vivimos un tiempo de grandes mayorías que solo tienen libertad para ser miserables con imaginarios de autonomías y emprendimiento; vivimos un tiempo de víctimas que se vuelcan contra víctimas y de oprimidos que eligen a sus opresores con imaginarios de liberación y de justicia social (Santos, 2017).

Es necesario revertir esta multiplicidad de imaginarios y discursos sobre las democracias, el "desarrollo" y la justicia social. Un camino para ello es observar y aprender de las luchas y resistencias que protagonizan los pueblos indígenas junto con otros luchadores sociales pues son pequeñas luces que no solo desenmascaran las narrativas hegemónicas, sino que muestran que los derechos no se otorgan, sino que se conquistan y se defienden.

\section{Reflexiones finales}

A lo largo de este artículo he querido hacer un recuento amplio sobre el ignominioso giro extractivista que recorre tanto a México como al resto del continente latinoamericano. El énfasis analítico se centró en los rostros del despojo que se ciernen en vastos territorios indígenas del suelo nacional, que puede comprenderse analizando las tramas económicas y jurídicas que sostienen el despojo, arrasando en su avance las autonomías reconocidas constitucionalmente a los pueblos indígenas, así como la razón del Estado que ha transitado del bien común a la custodia de los intereses de los grandes inversionistas, con el concomitante replanteamiento de la soberanía nacional, dejando como corolario una permanente violación de los derechos colectivos reconocidos a los pueblos indígenas y una devastación ecológica que se torna 
irreversible, situaciones que hemos querido mostrar son contestadas desde abajo, por pueblos y comunidades indígenas y campesinas.

Las tramas que sostienen dichos despojos se construyen desde diferentes trincheras: una es el giro del modelo de capitalista, que de acuerdo con especialistas obedece a la crisis del modelo de acumulación capitalista que viró del Consenso de Washington al Consenso de las Commodities ampliando sus fronteras a zonas marginales del capitalismo (Svampa, 20II) y, por otro lado, responde a la vorágine del consumo de tecnologías y de bienes que requieren como materia prima los minerales depositados mayoritariamente en el continente americano, especialmente en territorios indígenas.

En el avance del extractivismo minero se confrontan las imágenes de las grandes corporaciones mineras - mayoritariamente las empresas canadienses que concentran $70 \%$ de la inversión en México-, que acumulan millones de dólares que salen del país en forma de materias primas y son procesadas en otras latitudes. Emblemática de este proceso es la fotografía del dueño de $75 \%$ de las acciones de la minera canadiense Goldcorp Robert McEwen, sentado sobre Ioo ooo onzas de oro, y cuya fortuna se eleva a 83 millones de dólares (Garibay y Balzaretti, 2009). Frente a las imágenes de miles de indígenas, campesinos, ambientalistas y otros muchos ciudadanos que marchan contra las nuevas invasiones en calles, con las únicas armas de la resistencia que poseen, sus cuerpos, megáfonos, pancartas y mantas coloridas que denuncian los atropellos de las grandes corporaciones, apelando en su lucha a las instancias de justicia nacionales y en algunos casos supranacionales, exigiendo el cumplimiento de los derechos colectivos autonómicos, ambientales y humanos que jurídicamente les han sido reconocidos.

En esta batalla por los recursos del subsuelo, otra de las aristas está constituida por la confrontación de derechos: el construido por las grandes corporaciones trasnacionales, que de manera fáctica está colocado por encima del derecho internacional en materia de derechos humanos, el derecho nacional y el derecho indígena. De tal forma que sus contendientes deben desplegar una de serie de estrategias que van de las protestas callejeras al litigio estratégico.

Sobre la importancia del campo jurídico, Jean Comaroff y Jonh Comaroff (2009) hablan de una fetichización de la ley, que ocurre tanto en el norte como en el sur global. Muestran cómo especialmente en los países poscoloniales se han elaborado nuevas constituciones que son el sustento de los rostros contemporáneos de las naciones culturalmente plurales, es decir, se ha abandonado la vieja narrativa de homogeneidad política, cultural y jurídica. Se han creado nuevas leyes que sostienen a los nuevos Estados cuyas funciones de control siguen siendo centrales, pero 
no su rol en el destino del modelo económico. Pues junto con otros autores, como Mbembe, que estudia estas transformaciones en África, afirman que estamos ante la construcción legal de un "gobierno indirecto privado" en donde la soberanía se difumina en formas privatizadas de poder y acumulación, que dan legalidad a la rapiña presente en el sur global (citado por Comaroff y Comaroff, 2009: 15). En esta vía, el discurso de fortalecer una cultura de la legalidad permea prácticamente a todos los Estados y sectores sociales. Por ello, tanto los luchadores sociales como las mafias de delincuentes, las empresas y los ciudadanos comunes apelan a la ley en un escenario de gran desorden y violencia. En otras palabras, se trata de un escenario en donde la ley, el derecho, se utiliza como un arma de combate por todos los contendientes. Sin duda es una constatación relevante, pues ciertamente los intereses, las identidades, los derechos y las heridas están saturados de legalidad. Afirman con base en múltiples ejemplos que la propia política se está desplazando a los tribunales, pues conflictos que antes tenían lugar en los parlamentos, mediante protestas callejeras, campañas mediáticas, huelgas, boicots y bloqueos, tienden cada vez a abrirse camino por la vía judicial.

Como muestra de este desplazamiento podríamos mencionar que desde las filas de la propia institucionalidad del Estado existen voces y actores que han demostrado el daño que el nuevo extractivismo ocasiona al país, por ejemplo, la Comisión para el Diálogo con los Pueblos Indígenas (CDPI), dependiente de la Secretaría de Gobernación, elaboró en 2013 un estudio que documenta los daños y la relación inequitativa entre las empresas canadienses mineras que operan en el territorio mexicano, pero parecieran inaudibles. Los mismo ocurre con las decenas de estudios que especialistas han elaborado y que han documentado los procesos de despojo, las relaciones entre empresas, pueblos y regiones afectadas por el giro extractivista. Los sitios web están inundados de información sobre el despojo de tierras, territorios y sus adversas consecuencias; sin embargo, la respuesta gubernamental sigue siendo la misma: la minería es una actividad de interés público. Situación semejante se constata en los debates del Congreso de la Unión, por ejemplo, en 2014 la diputada Dolores Padierna de la bancada del Partido de la Revolución Democrática presentó una iniciativa de una nueva ley de minería, que recogía las propuestas de un gran número de organizaciones, pueblos indígenas y especialistas; sin embargo, su destino fue la congeladora. Por ello el diálogo o debate en y con o frente a instituciones gubernamentales es poco fértil, lo que ha llevado a trasladar las luchas al campo judicial. Ciertamente esto es una novedad, pues la ley no es ahora solamente el sostén del Estado; la guerra legal es también el campo de batalla de los débiles (utilizando los términos de los Comaroff), de los pueblos indígenas 
contra el extractivismo. Por ello, la única esperanza en el horizonte son las pocas pero significativas batallas jurídicas ganadas al extractivismo por pueblos indígenas como los nahuas, zapotecos, méphaas y wisrárikas de distintas etnorregiones, que con grandes costos sociales se han ido sumando. Por ello el análisis de las resistencias al giro extractivista se constituye como una tarea fundamental, pues parece que será la tónica de los siguientes años, y por lo tanto las resistencias sociales y jurídicas seguirán pintando el suelo mexicano.

\section{Referencias bibliográficas}

Agamben, Giorgio (2016), "Del Estado de derecho al estado de seguridad”, disponible en: <https://redfilosoficadeluruguay.wordpress.com/2016/or/05/ g-agamben-del-estado-de-derecho-al-estado-de-seguridad/> [consultado: 10-06-2017].

Amnistía Internacional, AI (2017), "Asesinados 437 ambientalistas y luchadores proDerechos Humanos en dos años", $M_{4}$ Movimiento Mesoamericano contra el Modelo Extractivo Minero. Estrategias por la Defensa de la Tierra $y$ el Territorio, 05 de octubre. Disponible en: <http://movimientom4. $\mathrm{org} / 2017 / \mathrm{Io} /$ asesinados-437-ambientalistas- $y$-activistas-proderechos-humanos-en-dos-anos/> [consulta: 10/10/2017].

Boege, Eckart (2013), "La minería industrial en territorios bioculturales de los pueblos indígenas. El despojo de los indígenas de sus territorios en el siglo xxI", Rebelión, 4 de junio. Disponible en: <http://www.rebelion. org/noticias/2013/6/169166.pdf> [consulta: 15/06/2017].

Breach, Miroslava (2008),"Habitantes de Chihuahua, hartos de abusos de mineras extranjeras", La Jormada, $\mathrm{I}^{\circ}$ de enero. Disponible en: http://www. jornada.unam.mx/2008/or/o2/index.php?section =estados\&article =O26niest [consulta: 02/II/2017].

Castro, Gustavo (2012), "La explotación minera en Chiapas el caso de Chicomuselo", Disponible en: <http://www.nacionmulticultural.unam.mx/ edespich/images/diagnostico_y_perspectivas/Economia_sociedad_y_ desarrollo/Eonomia_y_reproduccion_social/recuadros/3_la_explota cion_minera_en_chiapas_el_caso_de_chicomuselo.pdf $>$ [consulta: I8/06/2017]. 
Comaroff Jean y John Comaroff (2009), Violencia y ley en la poscolonia. Una reflexión sobre las complicidades Norte-Sur, Buenos Aires, Katz editores.

Comisión para el Diálogo con los Pueblos Indígenas, CDPI (2013), Estudio de la Minería en México. Un análisis comparado con Canadá, México: CDPI, Segob. Disponible en: <http://www.cdpim.gob.mx/v4/> [consulta: 25/07/2017].

García, Juan José (20I4), "Inicia construcción de complejo minero en la Sierra Tarahumara", Milenio, 3 de noviembre. Disponible en: <http://www. milenio.com/estados/Inicia_construccion_de_complejo_minero_en_ la_sierra_tarahumara-Cesar_Duarte_o_402560078.html> [consulta: 31/03/2017].

Garibay, Claudio (2017), "Clúster minero global, instauración de horizontes de coerción y resistencias en sociedades locales mexicana”, disponible en: <https://we.riseup.net/ecopol/garibay-claudio-2017-clúster-minero $+408593>$ [consulta: $02 / 03 / 2018$ ].

Garibay, Claudio y Alejandra Balzaretti (2009), "Goldcorp y la reciprocidad negativa en el paisaje minero de Mezcala, Guerrero", Desacatos, 30, mayo-agosto.

Garibay, Claudio, Andrés Boni, Francesco Panico y Pedro Urquijo (2014),"Corporación minera, colusión gubernamental y desposesión campesina. El caso de Goldcorp Inc. en Mazapil, Zacatecas", Desacatos, 44, enero-abril, Pp. II3-I42.

Gledhill, John (2014), "Seguridizar, reprimir, pacificar: una crítica de las nuevas guerras en América Latina”, en: Laura Valladares (coord.), Nuevas violencias en América Latina. Los derechos indígenas frente a las políticas neoextractivistas y las políticas de seguridad, México, UAm-Iztapalapa/ Juan Pablos Editor, pp. 31-62.

Gudynas, Eduardo (2009), "Diez tesis urgentes sobre el nuevo extractivismo. Contexto y demandas bajo el progresimo sudamericano actual", en: Jürgen Schuldt et al., "Extractivismo, politica y sociedad." Centro Andino de Acción Popular (CAAp) y Centro Latino Americano de Ecología Social (claes), Quito, noviembre, pp 187-225. Disponible en: <http:// www.gudynas.com/publicaciones/GudynasNuevoExtractivismoı Tesiso9x2.pdf> [consulta: 15/02/2018]. 
Harvey, David (2004),"El “nuevo" imperialismo. Acumulación por desposesión”, Socialist Register. Disponible en: <http://socialistregister.com/index. $\mathrm{php} / \mathrm{srv} /$ article/view/14997> [consulta: 15/02/2015].

Herreño, Ángel (2015), "Notas sobre el acceso a la justicia global corporativa por parte de las víctimas del desarrollo", El Otro Derecho, 5I, Colombia, Instituto Latinoamericano para una Sociedad y un Derecho Alternativo (ILSA), pp. I5-II7.

López, Francisco y Mayra Eslava (20II), El mineral o la vida. La legislación Minera en México, México, coapi-Red inpim. Disponible en: <http://www. lopezbarcenas.org/files/escritos/El_mineral_o_la_vida_o.pdf $>$ [consulta: 01/07/2017].

López, Francisco (2017), La vida o el mineral. Los cuatro ciclos del despojo minero en México, México, Akal.

Matías, Pedro (2015), "Emiten declaratoria sobre territorios libres de minería en Oaxaca", Proceso, 2142, 30 de noviembre. Disponible en <http:// www.proceso.com.mx/422110/emiten-declaratoria-sobre-territorioslibres-de-mineria-en-oaxaca> [consulta: 03/09/2017].

Merchand, Marco (2013), "El Estado en el proceso de acumulación por desposesión favorece la trasnacionalización de la minería de oro y plata en México", Paradigma Económico, 5(I), enero-junio, pp. 107-I4I. Disponible en: $<$ https://dialnet.unirioja.es/servlet/articulo?codigo=5954II7> [consulta: 03/09/2017].

Gobierno de la República GR (2014), "Programa de Desarrollo Minero 20132018", Diario Oficial de la Federación, o9 de mayo. Disponible en: $<$ http://www.dof.gob.mx/nota_detalle.php?codigo $=5344070 \%$ fecha $=09 / 05 / 2014>$ [consulta: 30/05/2017] .

Pérez, Sol (2014), Territorialidades contenciosas en México. El caso de las mineras, tesis de maestría inédita, México, unAM-Centro de Investigaciones en Geografía Ambiental.

Regeneración (2016),"Miles de indígenas declaran Veracruz y Puebla territorio libre de mineras y petroleras", Regeneración, 26 de febrero. Disponible en: <https://regeneracion.mx/miles-de-indigenas-declaran-vera cruz-y-puebla-territorio-libre-de-mineras-y-petroleras/ $>$ [consulta: 05/1I/2017].

Santos, Boaventura de Souza (2017), "Se necesitan horizontes". Disponible en: $<$ https://www.paginal2.com.ar/39597-se-necesitan-horizontes $>$ [consulta: OI/04/2018]. 
Svampa, Maristella (2012), "El consenso de los commodities, giro ecoterritorial y pensamiento crítico en América Latina", Observatorio Social en América Latina, XIII(32), noviembre, CLAcso, Buenos Aires, pp. 15-38. Disponible en: <http://biblioteca.clacso.edu.ar/clacso/osal/20120927103642/ OSAL32.pdf $>$ [consulta: Io/o9/2017].

Secretaría de Economía se (2014), "Ley Minera", Diario Oficial de la Federación, II de agosto. Disponible en <http://www.diputados.gob.mx/Leyes Biblio/pdf/I5I_IIO8I4.pdf > [consulta: 02/I2/2017].

Secretaría de Energía SE (2017), "De enero a junio de 2017 México registró I5 645.2 millones de dólares de Inversión Extranjera Directa", I5 de agosto. Disponible en: <https://www.gob.mx/se/prensa/de-eneroa-junio-de-20I7-mexico-registro-15-645-2-millones-de-dolares-deinversion-extranjera-directa $>$ [consulta: $15 / \mathrm{II} / 2017$ ].

Servicios y Asesoría para la Paz, Serapaz (2015),"Comunidades de la Montaña de Guerrero declaran su territorio libre de minería”, 23 de julio. Disponible en: <http://serapaz.org.mx/comunidades-de-la-montana-de-guerrero-declaran-su-territorio-libre-de-mineria/> [consulta: $18 / \mathrm{II} / 2017]$.

Toledo, Víctor (20II), "Batallas socio-ambientales en México”, Regeneración, II de abril. Disponible en: $<$ https://regeneracion. $\mathrm{mx} /$ batallas-socio-ambientales-en-territorios-de-mexico/> [consulta: 10/03/2017].

Tribunal Permanente de los Pueblos, тp (2014), Sentencia: Libre Comercio, violencia, impunidad y Derechos de los Pueblos en México (2011-2014). Disponible en: <http://mexico.indymedia.org/IMG/pdf/sentencia. pdf $>$ [consulta: 0I/05/2017].

Sierra, Ma. Teresa (en prensa),"Pueblos indígenas frente a la minería en México. Ecología de saberes en la lucha jurídica”.

Valladares, Laura (2008), "La política de la multiculturalidad en México y sus impactos en la movilización indígena. Avances y desafíos en el nuevo milenio", Identidades, etnicidad y racismo en América Latina, Ecuador, Flacso, pp. 289-310.

Valladares, Laura (2018), "El despojo de los territorios indígenas y las resistencias al extractivismo minero en México", E-Cadernos, Universidad de Coimbra.

Wacquant, LoIc (2009), Punishing the Poor: The Neoliberal Government of Social Insecurity, Londres, Duke University Press. 
Zibechi, Raúl (2015), "La minería es un mal negocio", América Latina en Movimiento, 2 de diciembre. Disponible en: <http://www.alainet.org/es/ articulo/173976> [consulta: 23/06/2017].

Laura R. Valladares de la Cruz

Doctora en Antropología, profesora investigadora del Departamento de Antropología de la UAM-Iztapalapa desde 200I, miembro del Sistema Nacional de Investigadores (Nivel I). Sus campos de investigación versan sobre los derechos de los pueblos indígenas, justicia y derechos de las mujeres y jóvenes indígenas, extractivismo y derechos indígenas, resistencia y movimientos sociales. Entre sus publicaciones están, "El despojo de los territorios indígenas y las resistencias al extractivismo minero en México", E-Cadernos, Universidad de Coimbra, Portugal, 2018, "Cosechando esperanzas a través de los cambios generacionales: del derecho de las mujeres al feminismo indígena culturalmente situado", gimtrap, México, 20I7, con Antonio Escobar Ohmstede, "Culturas políticas y movimientos étnicos en América Latina, en: Marta Casaús y Morna Macleod (coords.) América Latina entre el autoritarismo y la democratización 1930-2012, Colección Historia de las Culturas Políticas en España y América Latina, vol. vi. (2016), coordinó el libro colectivo Nuevas violencias en América Latina. Los derechos indígenas ante las políticas extractivistas y las politicas de seguridad, México, Uam-I/Juan Pablos editor, 2014.

Citar como: Laura R. Valladares de la Cruz (2018), "El asedio a las autonomías indígenas por el modelo minero extractivo en México", Iztapalapa. Revista de Ciencias Sociales y Humanidades, núm. 85, año 39, julio-diciembre de 20I8, ISSN: 2007-9176; pp. 103-I3I. Disponible en <http://revistaiztapalapa.izt.uam.mx/index.php/izt/issue/archive >. 